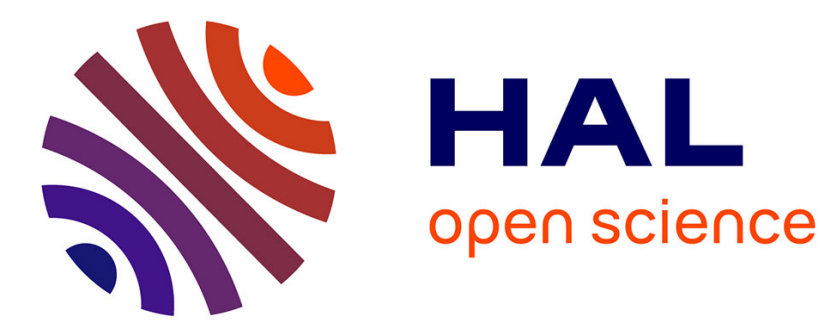

\title{
Strategies for the management of lecturer stress in feedback tutorials
}

Elizabeth Hartney

\section{To cite this version:}

Elizabeth Hartney. Strategies for the management of lecturer stress in feedback tutorials. Active Learning in Higher Education, 2007, 8 (1), pp.79-96. 10.1177/1469787407074119 . hal-00571958

\section{HAL Id: hal-00571958 \\ https://hal.science/hal-00571958}

Submitted on 1 Mar 2011

HAL is a multi-disciplinary open access archive for the deposit and dissemination of scientific research documents, whether they are published or not. The documents may come from teaching and research institutions in France or abroad, or from public or private research centers.
L'archive ouverte pluridisciplinaire HAL, est destinée au dépôt et à la diffusion de documents scientifiques de niveau recherche, publiés ou non, émanant des établissements d'enseignement et de recherche français ou étrangers, des laboratoires publics ou privés. 


\title{
Strategies for the management of lecturer stress in feedback tutorials
}

active learning in higher education

Copyright (C) 2007 SAGE Publications (London, Los Angeles, New Delhi and Singapore)

Vol 8(1): 79-96

DOI: $10.1177 / 1469787407074119$

ARTICLE

\author{
ELIZABETH HART NEY University of Greenwich, UK
}

\begin{abstract}
The process of providing students with individual feedback on assessed work was identified as a source of lecturer stress (Stough and Emmer, 1998). An action research approach was used to address the following research question. What approaches to providing students with feedback minimize lecturer stress? Data were collected using written feedback mark-sheets and a reflective diary. Findings indicated that negative expectations, student emotion, challenges from students and lack of control were identified as lecturer stressors and that a variety of strategies gleaned from recent literature were found to be effective in minimizing lecturer stress. Although shortcomings in the methodology of the study limit the generalizability of the findings, the action research provides a useful starting point for thinking about the impact of feedback strategy on lecturer stress.
\end{abstract}

KEYWORDS: action research, feedback, lecturer stress, stress

management, student emotion

\section{Introduction}

\section{Lecturer stress}

Early definitions of stress focused on the higher level of physical stimulation, also known as the 'fight or flight' response, that occurs in response to a threat (Cannon, 1932), or to cope with events that cause stress, known as 'stressors' (Selye, 1956). These physical reactions were considered to be adaptive. Later definitions of stress emphasized the context and situations in which stress occurs, focusing on issues such as life events (Holmes and Rahe, 1967). More recently, Lazarus and Folkman (1984) developed the idea that stress does not simply happen automatically, but that we go through a complex series of 'appraisals' or judgements of the stress-inducing situation, which affect how 'stressed-out' we actually become. It is this process of appraisal 
that allows us to respond to stress in different ways. Each of these definitions provides insight into aspects of stress. For the purposes of the current study, stress is defined as the physical and psychological response experienced by a lecturer in reaction to perceived challenge or difficulty. Readers should note that the focus here is on negative stress as opposed to positive stress (or 'eustress'). For more details on the distinctions between positive and negative stress in teachers, refer to Hartney (2006).

Research by HEFCE (2003) shows that stress from working in Higher Education is significantly greater than stress involved in working in other types of industry. Furthermore, of all higher educational institution employees, academic non-clinical staff (that is, lecturers) are the most stressed. This finding is supported by previous research by Blix et al. (1994), which showed that university lecturers are significantly more stressed than support staff at the same institution, and as many as 66 per cent of university lecturers perceive stress at work at least 50 per cent of the time. Furthermore, university lecturers are significantly more stressed than medical school teachers (Walford, 2004).

HEFCE's (2003) research identified work relationships as a major stressor for lecturers, and relationships with students have been identified by Taris et al. (2004) as being potentially stressful for teachers. A time when the studentlecturer relationship is particularly prone to provoking stress in lecturers is when the students' work must be criticized for feedback purposes, resulting in challenging or difficult behaviour from students (Stough and Emmer, 1998). Lecturers may also be concerned that students will be upset by criticism or poor grades, a concern that has been substantiated by Young (2000).

\section{Effects of feedback on students}

Young's (2000) research into mature students' feelings about feedback on assignments indicated that anxiety is universal among students submitting their first assignment, but that responses to feedback were related to self esteem rather than ability, grade received, and whether positive or negative comments were provided. Whilst students with high self esteem value all feedback, positive or negative, students with low self esteem will interpret even positive feedback negatively, indicating at the very least, a balance between positive and negative feedback is needed. However, in practice this can be difficult in cases of poor quality work, where many areas for improvement are identified, and very little positive feedback that can realistically be given.

Young's (2000) research also revealed students' emotional responses to and attributions about feedback received. Students with high self esteem, despite feeling all feedback could potentially be acted upon, considered it to be the fault of the assessor if they did not get the mark they expected. 
They also felt entitled to an explanation, tended to become angry rather than upset, and directed emotion at the assessor rather than at themselves. In contrast, students with low self esteem felt upset rather than angry, and would consider simply giving up rather than challenging the assessor. Both types of emotional response are likely to increase lecturer stress (Stough and Emmer, 1998).

Smith and King (2004) argued that attribution theory, which is concerned with the way people attribute causality to events, is applicable to the process of providing students with feedback. Attribution theory is well established within social psychology, and the body of research into attribution theory has revealed various biases which are concerned with the individual protecting their own self image (Weiner, 1986, 2000; Weiner and Kukla, 1970). Students vary in their attribution of the causes of outcomes of submitted work as either internal, that is, the causes lie within the students themselves, or external, that is, the causes of the outcomes are due to factors outside of themselves. Smith and King (2004) argued that when feedback is critical of the work, learners are likely to blame the person giving the feedback (rather than to analyse the content of the feedback), whereas praise is typically internalized. This is consistent with other applications of attribution theory, in which people attribute causes in ways that minimize blame of themselves for shortcomings or failures, but that maximize taking personal responsibility for successes (Hogg and Vaughn, 1995).

Stough and Emmer's (1998) research questions whether feedback is even of benefit in all cases. Although teacher participants felt feedback was an important part of learning, both students and teachers interviewed felt that students' emotional reactions to the feedback could actually inhibit learning. Similarly, in their review of the literature, Smith and King (2004) noted that in some circumstances, providing feedback to students may actually retard performance, particularly if it is overly harsh, negative and direct, thereby directing the students' attention to meta-task processes (such as self concept), rather than to the task itself. Furthermore, research has shown that teacher praise and feedback affects students in numerous ways, including their perceptions of the classroom environment, their relationships with their teachers, and student satisfaction (Burnett, 2002).

\section{Lecturer reactions to providing feedback}

However, feedback is well-documented as a useful tool in the learning process. Indeed, learning theory, an important component of psychological theory generally, is based on the idea of feedback determining what is learned through 'reinforcement', and feedback has been shown to enhance learning by affirming accurate responses or correcting errors (Thorndike, 1927). 
Evidence showing the importance of feedback in teaching and learning has been demonstrated in numerous research contexts, including teacher training (Leach and Conto, 1999), training mentally retarded students (van Vonderen and de Bresser, 2005), and classroom learning (Brosvic et al, 2005).

Stough and Emmer's (1998) research is perhaps unique in its focus on lecturers' emotions in relation to providing student feedback. They conducted interviews with college teachers and their students, specifically focusing on the emotions experienced by teachers when providing students with feedback on assessed work. They found:

Teachers viewed feedback sessions as an opportunity to communicate knowledge and to improve student understanding in areas revealed as weak ... [and] students profited from being involved in the process ... however ... students who made errors on exams often would, if allowed the opportunity, challenge the teacher and exhibit considerable resistance. Dealing with such challenges aroused a variety of negative emotions in these teachers, especially when students persisted, displayed emotion, refused to admit their own lack of understanding, or were supported by other students. The strategies developed by teachers in our study reflected their attempts to organize feedback sessions in ways that were consistent with their goals and beliefs, and yet limited their own frustration, annoyance, anger, anxiety, and related stress in response to the feedback session. (Stough and Emmer, 1998: 358)

Stough and Emmer (1998) identified a variety of negative emotions experienced by teachers in this context. The emotions described by teachers included fear of conflict with students, anger at the students' response to feedback, and guilt, if the teachers felt they themselves had been inappropriately emotional. The teachers all had negative expectations about the feedback sessions, due either to past experience or to comments heard from other teachers. The teachers had strong expectations of negative reactions from particular students, often low achievers or high achievers who received a lower grade than was typical for them. The latter were actually considered more problematic, because of the high achieving students' skill in argument and unwillingness to accept teachers' explanations.

Smith and King's (2004) explanation goes some way to elucidating the process by which students' reactions to feedback can affect lecturer stress. If the lecturer is focused on providing critical feedback, in the hope that students will learn from their mistakes, the lecturer may be inadvertently encouraging the students to blame the lecturer, rather than to take responsibility for improving their own work. This consequence may be expressed directly, by the student challenging the lecturer (for example, by arguing with or discounting negative feedback), or indirectly (for example, non-verbally through expression of negative emotions, or simply by failing to make improvements in performance in relation to specific feedback). 
Providing feedback can cause lecturers both short-term and long-term stress. In the short-term, being faced with unhappy or angry students is stressful at the time of the interaction. In the long term, the end result of the lecturer's work in providing feedback being dissatisfied students who do not seem to learn, may leave the lecturer feeling that no matter how carefully areas for improvement are identified, the students fail to listen, care or take notice. Long-term stress can result from such negation of the lecturer's professional role.

It is not surprising, therefore, that providing students with feedback can result in lecturer stress. Taken together, the results of these studies indicate that the process of providing feedback to students is a delicate matter, which can have far-reaching consequences for lecturers as well as for students. The focus on lecturer stress is unusual, as typically lecturers are concerned with the well-being of their students, rather than their own well-being. Although it is apparent that providing students with feedback can sometimes be stressful, and may provoke emotional reactions in students and lecturers, little is understood about the relationship between providing students with individual feedback and how this might impact stress in lecturers.

This study poses the following question. What approaches to providing students with feedback minimize lecturer stress? This question will be addressed by looking at lecturer experiences of stress during feedback sessions, aiming to provide a better understanding of the issues contributing to lecturer stress within the lecturer-student relationship. Strategies implied by literature (Stough and Emmer, 1998) will be systematically applied and evaluated, in order to identify ways that lecturers can adapt their own feedback techniques in ways that reduce their own stress.

\section{Methodology}

The research was conducted and data were collected solely by the author. The research question sets out to identify what approaches to providing students with feedback minimize lecturer stress. This was addressed by exploring lecturer stress during feedback tutorials, before and after an intervention consisting of the use of feedback strategies suggested by the literature. The action research cycle comprised several sequential stages (Bruner, 1960), and is described below as a three-stage process.

\section{Stage one: pre-intervention}

A group of approximately 180 first year psychology students completed a small research study and wrote up a lab report as a piece of research methods coursework. This was the third of four lab reports to be completed for 
this course. The course was taught by a team of tutors, each focusing on different aspects of the course (theory, statistics, and practical lab sessions). According to departmental policy, the coursework was marked by the students' personal tutor, who in the case of the researcher, was not responsible for any teaching on this course. As their personal tutor, the researcher marked the coursework of a sub-group of approximately 20 students, using guidelines provided by staff teaching the course, and providing written feedback to the students using standardized feedback marksheets (used by all personal tutors in the department, in order to ensure consistency). The feedback marksheets have two sections. The first section contains a series of criteria on which the work is rated, based on aspects identified departmentally as important components of written work. The second section is open-ended, and is intended for comments on the work. It is the contents of this second section that was adjusted and analysed in the current research.

Prior to the coursework being returned, informed consent was obtained from all students consistent with the BPS's (2004) ethical guidelines on research. The researcher then returned the coursework to students in individual feedback sessions, during which the student was given the work, told their mark (which was a composite of marks for each section of the report), and encouraged to read the written feedback and ask for clarification if necessary. The lecturer then explained further the rationale for any marking decisions or feedback comments in response to the students' questions. As soon as possible after each tutorial had been completed, the researcher recorded her own thoughts, feelings and experiences of stress during the tutorial in a reflective diary. The entries in the diary varied in length depending on the intensity and extent of emotion and/or stress experienced. The diary was used as a source of raw data, which were analysed qualitatively using grounded theory (Glaser and Strauss, 1967).

\section{Stage two: developing the intervention}

Copies of the feedback mark-sheets provided to the students in the preintervention stage were analysed. At this point, strategies which may reduce lecturer stress were identified in the literature on feedback. These are summarized in Table 1.

Nine strategies were identified in total, although four strategies were considered to be more appropriate for change at the course or programme level, rather than the level of one-to-one dialogue, and so were not used in this study. These four strategies were presented to the department for consideration, and readers are directed to the source references listed in Table 1 for more details. An overview of each of the remaining five strategies used in the intervention is provided below. 
Table 1 Strategies for reducing lecturer stress whilst providing effective feedback

\begin{tabular}{|c|c|c|}
\hline Source & Strategy & Implementation \\
\hline Stough \& Emmer (1998) & $\begin{array}{l}\text { 'Masking' - teacher conceals } \\
\text { own emotion }\end{array}$ & $\begin{array}{l}\text { Action research } \\
\text { (in tutorial) }\end{array}$ \\
\hline Stough \& Emmer (1998) & $\begin{array}{l}\text { 'Privatization' - student and } \\
\text { teacher discuss feedback } \\
\text { privately }\end{array}$ & Course/Programme* \\
\hline Stough \& Emmer (1998) & $\begin{array}{l}\text { 'Structured feedback' - 'answers' } \\
\text { are provided }\end{array}$ & Course/Programme* \\
\hline Stough \& Emmer (1998) & $\begin{array}{l}\text { 'Discussion' - students talk } \\
\text { in groups about feedback }\end{array}$ & Course/Programme* \\
\hline Smith \& King (2004) & $\begin{array}{l}\text { 'Low intensity' feedback - use } \\
\text { of brief, indirect, moderate } \\
\text { language }\end{array}$ & $\begin{array}{l}\text { Action research } \\
\text { (written) }\end{array}$ \\
\hline Burnett (2002) & $\begin{array}{l}\text { Decrease negative feedback, } \\
\text { increase general praise, } \\
\text { effort-related and ability } \\
\text { feedback }\end{array}$ & $\begin{array}{l}\text { Action research } \\
\text { (written) }\end{array}$ \\
\hline Young (2000) & $\begin{array}{l}\text { Present feedback in terms of: } \\
\text { (1) Strengths and } \\
\text { (2) Action plan }\end{array}$ & $\begin{array}{l}\text { Action research } \\
\text { (written) }\end{array}$ \\
\hline Young (2000) & $\begin{array}{l}\text { 'Depersonalize' - comment } \\
\text { on the work, not the student }\end{array}$ & $\begin{array}{l}\text { Action research } \\
\text { (written) }\end{array}$ \\
\hline Mutch (2003) & $\begin{array}{l}\text { Teach students how to use } \\
\text { feedback }\end{array}$ & Course/Programme* \\
\hline
\end{tabular}

${ }^{*}$ Course/Programme refers to recommendations which were developed when a strategy was identified that was appropriate for a change at course/programme level.

\section{Masking}

This was a strategy used by lecturers in Stough and Emmer's (1998) study, in which the lecturer conceals their own emotion behind a 'mask' of a neutral, calm facial expression and body language. Masking is helpful in tutorials in several ways. Firstly, it provides a model of how to behave in tutorials, demonstrating leadership on the part of the lecturer. Secondly, it prevents the dialogue from escalating into an argument or inappropriately emotional exchange. Thirdly, it protects the lecturer from appearing vulnerable in front of the student, thus reinforcing credibility.

\section{Low intensity feedback}

This was a strategy found to be effective by Smith and King (2004), in which brief, indirect, moderate language was used in communicating feedback. This strategy was used on the written feedback marksheets as well as 
in the tutorial. This strategy was helpful in providing the information in simple, straightforward language that the student could readily understand, without being distracted by struggling with ambiguous meanings, ideas that were beyond their current level of knowledge and ability, or force of argument. It also prevented the student's emotional responses being triggered by provocative language. This is contrary to the belief that some lecturers have, namely, that force of argument will have a greater impact on students and will jolt them into taking the feedback seriously.

\section{Decrease negative feedback, increase general praise, effort- related and ability feedback}

These approaches were, in combination, implied by the findings of Burnett (2002). It should be pointed out that there is not necessarily a reduction in feedback overall, but rather, that negative feedback is balanced with positive feedback, and negative feedback is presented more efficiently while still identifying areas for improvement. This strategy is helpful because it makes the feedback more accessible to students. Being drawn in by praise for the work they have done, they are more able to appreciate areas for improvement. As with 'low intensity' feedback, it is more effective to provide brief points on what needs to be changed that students will pay attention to, than to provide elaborate, exclusively critical feedback that fails to acknowledge any success on the part of the student, and simply makes them feel they have wasted their time and effort. It should be noted that many students also find negative feedback humiliating, so the more it is balanced by acknowledgement of what they have done well, the more likely they are to engage with the process of trying harder next time.

\section{Present feedback in terms of strengths and an action plan}

This style of presentation is based on the work of Young (2000). This strategy is helpful in several ways. Firstly, it provides a balance between positive and constructive feedback consistently across students. Secondly, it is sensitive to the students' feelings, making them less likely to become inappropriately emotional. Thirdly, rather than being a once-and-for-all judgement on the students' work, it reinforces the idea of feedback as part of a learning process, and focuses the student on taking a positive approach to future work.

\section{Depersonalize feedback}

Young's (2000) observations also indicated this strategy, meaning the lecturer should comment on the work, not on the student. This is important in both protecting the students' self esteem, and in helping the student to recognize that negative feedback is not personal criticism, but objective commentary on a piece of work. Related to this is developing the students' belief that the learning process is dynamic, and that their work can be 
improved next time if feedback is taken on board. It is all too easy, however, for lecturers to fall into the trap of personalizing work in an attempt to draw the student in, using commentary such as: 'You need to do more reading', or 'You need to include more analysis', rather than alternatives such as: 'The introduction would be improved by a broader literature review', or 'The argument would be strengthened by more analysis'.

\section{Stage three: implementing and evaluating the intervention}

The same group of first year students completed another piece of coursework, the fourth of four lab reports for the same research methods course, in the normal way. The researcher marked this in the normal way, using the guidelines provided by teaching staff on the course, but the feedback provided on the open-ended section of the feedback marksheets was modified according to the intervention strategies described above. The procedure used for marking work according to these strategies was quite straightforward, and was largely a matter of style. The blank section of the feedback form for comments was divided into two equal sections (thus balancing positive and negative feedback). Each section was given a brief title, the first being 'Strengths', the second being 'Action Plan'. Within each of these two sections, points were included in bullet form. Both praise and suggestions for improvement were matched to the department's criteria for the classification of degree work, and comments related to how well the work demonstrated meeting or failing to meet these criteria. For example, for poorer work, in the pre-intervention stage little or no praise was given, but in the action research intervention, comments such as 'The work demonstrates an effort to focus on the topic set', and 'The report is of the correct length' acknowledge the fact that the student has made efforts to meet the basic requirements, although those efforts might appear minimal to the lecturer. This meant that students were being acknowledged for aspects of their work that are often overlooked or taken for granted by markers.

It should be noted that feedback was not limited, as comments continued to be written directly on to the script (although the new style of language was used). Therefore, students did not miss out on information they needed. Furthermore, students were reminded of the departmental criteria for grading work, which was included in their handbook. The action research process was then discussed with a critical friend (McNiff et al., 1996), prior to meeting with students in tutorials and providing feedback on written work.

All students who attended tutorials to collect their work were provided with verbal feedback using the intervention strategies. The effectiveness of the strategies was evaluated in relation to students' responses to, and readiness to accept, feedback, and lecturer stress, which were again recorded as 
thoughts, feelings and experiences of stress in the reflective diary. As the focus of the research was the lecturer's experience, rather than that of the students, data were not collected on the students' experiences of the tutorials. This decision was intended to avoid adding any complications to the process of giving feedback, which would be introduced if students were asked about their feelings and perceptions. For example, if a student had received a poor grade, and was then asked to reflect on their feelings about the feedback session, it would be very difficult for that student to separate their feelings (such as disappointment, frustration, embarrassment, etc.), from their feelings about the session itself, and asking students to do so may have invalidated the findings by introducing more emotion into the interaction. Furthermore, there are additional ethical concerns which are raised by encouraging students to reflect on their feelings, particularly if those feelings are negative.

Finally, the data recorded on the feedback sheets before and after the intervention were analysed using content analysis on the work of six students. This sample consisted of those students who had attended tutorials to collect coursework on both occasions (pre-intervention and intervention). The content analysis was similar to that of Mutch (2003), using categories identified in the literature which were extended to include categories which accounted for a large proportion of the written feedback. This was used to examine the change in types of feedback used before and after implementing the strategies.

\section{Results}

\section{Pre-intervention}

Four themes focused on stressors emerged from the data recorded in the reflective diary, which are presented in Table 2, along with examples of each. These four stressors were: negative expectation of the tutorial, student emotion, challenges from students, and lack of control.

\section{Negative expectation of tutorial}

This theme relates to the lecturer's awareness of her own stress levels rising even before the tutorial had taken place. This anticipatory stress was observed by the lecturer, in response to thoughts or sensory input related to the impending tutorial. In the example given in Table 1, the student concerned was one who had been consistently demanding throughout the lecturer's relationship with them. However, the identification of stress occurring even prior to the tutorial beginning, shows that the lecturer is primed to become more stressed in the event of challenges from the student. 
Table 2 Lecturer stressors related to feedback provision

\begin{tabular}{|c|c|}
\hline Stressor & Example \\
\hline Negative expectation of tutorial & $\begin{array}{l}\text { 'The second student, Mr A, was waiting } \\
\text { outside as Ms D left, and as I heard them } \\
\text { exchanging greetings outside my office } \\
\text { my stress levels started to rise, even } \\
\text { before Mr A came into the room.' } \\
14 \text { March } 2005\end{array}$ \\
\hline \multirow[t]{2}{*}{ Student emotion } & $\begin{array}{l}\text { 'Body language - a lack of response or } \\
\text { appeared bored or unengaged in the } \\
\text { process ... (eg. Ms B; Ms C).This included } \\
\text { a lack of eye contact or a glazed expression, } \\
\text { slumped posture, minimal response or } \\
\text { comment.' } 28 \text { February } 2005\end{array}$ \\
\hline & $\begin{array}{l}\text { 'While at first I found Mr A's apparent } \\
\text { vulnerability reasonable, over time ... they } \\
\text { trigger feelings of being manipulated. } \\
\text { Such characteristics include ... [subservient] } \\
\text { body language ... whiny, pleading tone, } \\
\text { as if he is being denied basic needs... } \\
\text { Facial expressions [which] range from } \\
\text { overly dramatic expressions of anxiety, } \\
\text { to condescending disapproval, and } \\
\text { the anger of the oppressed.' } \\
8 \text { March } 2005\end{array}$ \\
\hline Challenges from students & $\begin{array}{l}\text { '...every suggestion I make is discounted } \\
\text { by the student, every comment challenged, } \\
\text { thus turning the whole exercise into a long } \\
\text { argument... he has ... put enormous pressure } \\
\text { on me to account for my own marking } \\
\text { decisions and the University's systems. } \\
\text { At the end, he does not demonstrate } \\
\text { acceptance of what I have offered.' } \\
8 \text { March } 2005\end{array}$ \\
\hline Lack of control & $\begin{array}{l}\text { 'My feelings of lack of control of the situation } \\
\text {... he has wasted much of my time, and } \\
\text { completely ignored the needs of me and other } \\
\text { students. This makes me feel controlled by the } \\
\text { student, rather than being in control. I then } \\
\text { feel I have to apologise to any other students } \\
\text { who have been kept waiting, when in fact } \\
\text { I was pressurized into the delay.' } \\
8 \text { March } 2005\end{array}$ \\
\hline
\end{tabular}




\section{Student emotion}

This theme relates to any negative emotion of the student perceived by the lecturer. Two contrasting emotional responses are presented in Table 1, boredom and distress. The lecturer could not ignore these expressions of emotion, as an individual tutorial is concerned with counselling a student academically, and thus requires attention to be paid to the responses of the student to feedback. The lecturer's goal is to support and encourage the student, but the lecturer was met with a negative emotional response. Being non-verbal in nature, this negative emotional response had the effect of communicating defensiveness, disapproval or disagreement to the lecturer (without the student taking responsibility for this communication). This left the lecturer feeling uncomfortable with the interaction, and dissatisfied professionally.

\section{Challenges from students}

This includes direct disagreement, excuses, and arguments against negative feedback being suggested by the lecturer. This was most frustrating when a student was more concerned with defending their poor work than with learning how to do better next time, as it negated the purpose of the feedback.

\section{Lack of control}

This theme tended to come up in relation to occurrences of the student not respecting boundaries set by the lecturer. The example in Table 1 occurred when a student demanded more time than was allocated to them, causing the lecturer to become increasingly stressed with the growing awareness of keeping the other students waiting.

\section{Post-intervention}

A comparison between the content of feedback before and after implementing strategies is presented in Table 3. The content analysis shows an overall reduction in occurrences of negative feedback by more than half, with 32 pieces of negative feedback being given prior to the intervention, and 14 being given after the intervention. In contrast, positive feedback doubled, with only 4 pieces of positive feedback being given prior to the intervention, and 8 being given afterwards.

Nonetheless, it should be noted that there is still much more negative than positive feedback. After the intervention, specific criticism has been completely replaced by advice, which is still the most commonly given form of feedback. The number of comments referring directly to the student has decreased considerably, with an increase in comments referring to the work. General praise, effort related and ability related feedback remain the weakest areas in terms of feedback provided. 
Table 3 Content analysis of occurrences of feedback characteristics before and after intervention

\begin{tabular}{|c|c|c|c|}
\hline $\begin{array}{l}\text { Feedback } \\
\text { characteristic }\end{array}$ & $\begin{array}{l}\text { Occurrences } \\
\text { before } \\
\text { intervention }\end{array}$ & $\begin{array}{l}\text { Occurrences } \\
\text { after } \\
\text { intervention }\end{array}$ & Example \\
\hline \multicolumn{4}{|l|}{ Positive feedback } \\
\hline General praise* & 0 & 2 & $\begin{array}{l}\text { 'Generally very good } \\
\text { work' (Ms E) }\end{array}$ \\
\hline Specific praise ${ }^{\dagger}$ & 3 & 5 & $\begin{array}{l}\text { 'Good organization } \\
\text { of the methods } \\
\text { section' (Ms C) }\end{array}$ \\
\hline Effort related ${ }^{*}$ & 1 & 0 & $\begin{array}{l}\text { 'A good effort on the } \\
\text { intro' (Ms D) }\end{array}$ \\
\hline Ability related* & 0 & 1 & $\begin{array}{l}\text { 'Good understanding of } \\
\text { theoretical issues } \\
\text { demonstrated' (Mr A) }\end{array}$ \\
\hline Total Positive feedback & 4 & 8 & \\
\hline \multicolumn{4}{|l|}{ Negative feedback } \\
\hline Specific criticism ${ }^{\dagger}$ & 12 & 0 & $\begin{array}{l}\text { 'Your introduction is } \\
\text { very unclear' (Ms C) }\end{array}$ \\
\hline Indirect criticism (advice) ${ }^{\dagger}$ & 20 & 14 & $\begin{array}{l}\text { 'Proof read prior to } \\
\text { handing in' (Ms F) }\end{array}$ \\
\hline Total Negative feedback & 32 & 14 & \\
\hline \multicolumn{4}{|l|}{$\begin{array}{l}\text { Other feedback } \\
\text { characteristics }\end{array}$} \\
\hline Comment on student ${ }^{*}$ & 17 & 5 & $\begin{array}{l}\text { 'Your results would be } \\
\text { clearer if you reported } \\
\text { each t-test separately' } \\
\text { (Ms F) }\end{array}$ \\
\hline Comment on work* & 2 & 12 & $\begin{array}{l}\text { 'Any details of } \\
\text { questionnaires should } \\
\text { come under materials, } \\
\text { not procedure' (Ms B) }\end{array}$ \\
\hline 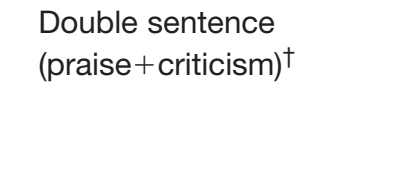 & 5 & 0 & $\begin{array}{l}\text { 'Your discussion } \\
\text { meets minimum } \\
\text { requirements, but is } \\
\text { much too brief' (Ms B) }\end{array}$ \\
\hline
\end{tabular}

*Characteristics based on literature review.

${ }^{\dagger}$ Characteristics based on content of feedback. 
The analysis revealed an additional issue that may be counter-productive the use of double sentences, where a criticism was added on to praise. On reflection, this was intended as an attempt to provide balanced feedback. However, it could have the opposite effect by negating the effect of the praise.

Brevity and indirectness were important to low intensity feedback, therefore the overall reduction in feedback volume, along with proportionally greater indirect feedback in relation to specific criticisms, are interpreted positively.

Students responded positively to the changes in feedback, and there was no lecturer stress reported in the reflective diary once the strategies were used.

\section{Discussion}

The results showed that the strategies identified in the literature to giving written feedback to students impacted positively on lecturer stress, as the tutorials were perceived as highly stressful prior to the intervention, and not stressful after implementing changes to the style of feedback. Overall, the increase in positive feedback and improved balance between positive and negative feedback characteristics made the experience of giving feedback more enjoyable. In addition, students in receipt of the feedback seemed more satisfied with their feedback and did not present any challenges during or after the intervention. This supports the use of feedback strategies identified within Burnett (2002), Smith and King (2004), Stough and Emmer (1998) and Young (2000), albeit collectively rather than individually.

Each of the strategies identified in the literature had the effect of addressing the stressors of student emotion, challenges from students, and lack of control by making the feedback process less emotional and provocative, and focusing the feedback on future work, rather than current deficiencies. Indirectly, this should have the effect, over time, of reducing the lecturer's negative expectations of tutorials, as past experiences are replaced with more positive experiences.

With widening participation, many first year students have to improve the quality of their work a great deal in order to produce work of the required standard in the second and third years of their degrees. The action plan focused on the main criteria needed to raise the grade by one classification, for example, from a fail to a third class pass, or from a third class pass to a lower second. Similarly, for higher quality work, for example, work of upper second class standard, positive feedback praised factors such as broad reading and critical analysis, whilst the action plan focused on raising the quality of the work to a first. In all cases, the wording used was simple, objective, moderate, and impersonal.

Challenges from students are often necessary during tutorials for students to clarify their understanding on issues where they feel they have had 
conflicting advice. However, there is a fine line between students clarifying their own understanding, and accusing the lecturer of giving incorrect or invalid feedback. As with the more passive 'student emotion', often the stress is caused by what is implied rather than what is said, through nonverbal communication such as tone of voice, sarcasm and body language.

The tension between being flexible and responsive to the individual student's needs, with needing to meet the other students' needs can be stressful to the lecturer. Setting boundaries is particularly important with students who do not respect them, because as adults, students must be negotiated with rather than directed.

However, it is difficult to accurately evaluate the observations reported in this study, as they were confounded by the fact that the post-intervention assignment was the final piece of work being returned to students, so there was less pressure on students to understand and incorporate feedback than there had been previously. Furthermore, the lower stress levels experienced may have been a function of student learning from the earlier feedback session rather than simply a result of improved feedback practices. In addition, with the focus of the action research being lecturer stress, it should be noted that as the final feedback tutorials of the year, they were less stressful. Future research should take into account the waxing and waning of stress for students and lecturers throughout the academic year, and build in a process by which student learning and adaptation to the feedback process is taken into account. One potential remedy would be to use a split-half approach, whereby half of the sample received the intervention and the other half did not, and to compare the results of the two groups. However, this raises ethical concerns regarding the potential consequences for students and their grades.

A related weakness of the current research is that students were not actively involved in the research. Feedback was adapted from the lecturer's point of view, and no data were collected from students relating to their perceptions of the experience of receiving feedback. It is not possible to claim to be less biased in my reflective point of view than the students would be (Winter, 1996). Furthermore, the tendency to introspection arising from reflective practice can 'lead to incapacitation, the potential to neglect the objectives of study in favour of a reflexive commentary ... and the difficulty of understanding and developing self-awareness' (Waterman, 1998: 104). Without active student involvement, the research is not truly collaborative. This could be overcome in future research by collecting and cross referencing data from both lecturers and students, an approach which proved effective when used by Stough and Emmer (1998). However, as stated previously in the methodology, the research process itself would be affected by students being encouraged to reflect on their experience of the tutorial, 
and this may also affect the student-lecturer relationship, thus impacting on post-intervention findings.

The grounding of the research in a specific work-site context limits its generalizability (Denscombe, 1998). In addition, the small sample size used in the current study can only provide a very limited snapshot of the effectiveness of the intervention. A more in-depth study with more rigorous data collection techniques and a larger sample size would be required to demonstrate whether the intervention was truly effective. Furthermore, the results indicated support for the feedback strategies collectively, rather than individually. Further research would be needed to determine how individual strategies are effective, and the ways in which they are effective. Again, including a student sample to provide an evaluation of each strategy would be helpful in this regard.

A final area of research which would build on the current study concerns lecturer characteristics. Many individual differences between lecturers may impact on the extent to which they experience stress whilst providing students with feedback. Possible variables include personality, self esteem, and number of years' experience. The use of quantitative methods, such as validated instruments for the measurement of stress and other variables, would be more conducive to hypothesis testing.

Despite an appropriate level of caution in interpreting the findings, from a professional point of view, the findings provide a starting point for lecturers to think about and adapt their practices in giving feedback. As well as incorporating the strategies described above, it may be helpful for lecturers to consider how their own responses to feedback as students may have affected their current views of the process. After all, those students who go on to become lecturers are not representative of students in general. Many academics, as students, adapted well to the rigours of higher education, and yet many of their current students, particularly those who are not so well adapted to the expectations of academic life, may have entirely different needs, preferences and learning styles. If, for example, a lecturer had a positive approach to receiving feedback, they may find it difficult to relate to students who do not collect their work or respond to feedback, resulting in negative and possibly inaccurate judgements of students' motivations, poor student-lecturer communication and increased lecturer stress.

In conclusion, lecturer stress in feedback tutorials appears to be directly related to the strategies used by the lecturer in giving feedback, both verbally and in writing. A number of strategies for giving effective feedback whilst minimizing lecturer stress were adapted from the literature, and effectively utilized in providing students with feedback on assignments. While more detailed research is needed to verify these 
findings, the research presented here provides a useful starting point for thinking about the impact of feedback strategy on lecturer stress, student-lecturer relationships and potential impact on student learning. By incorporating these strategies into their feedback practices, lecturers can maximize the effectiveness of their feedback and reduce their own stress.

\section{Acknowledgements}

The author would like to thank the students who participated in this study, and Isle Towler and Dr Mitchell Longstaff of the University of Greenwich for useful discussion and comments on this work.

\section{References}

BPS (2004) Code of Conduct, Ethical Principles and Guidelines. Leicester: British Psychological Society.

BliX, A., CRUise, R., Mitchell, B. \& BliX, G. (1994) 'Occupational Stress among

University Teachers', Educational Research 36(2): 157-69.

BROSVIC, G., EPSTEIN, M., COOK, M. \& DiHOFF, R. (2005) 'Efficacy of Error for the

Correction of Initially Incorrect Assumptions and of Feedback for the Affirmation

of Correct Responding: Learning in the Classroom', Psychological Record 55(3):

401-18.

BRuner, J. (1960) The Process of Education. Harvard: Harvard University Press.

BurnetT, P. (2002) 'Teacher Praise and Feedback and Students' Perceptions of the

Classroom Environment', Educational Psychology 22(1): 5-16.

CAnNon, W. B. (1932) TheWisdom of the Body. New York: Norton.

Denscombe, M. (1998) The Good Research Guide. Buckingham: Open University Press.

GLASeR, B. \& StRauss, A. (1967) The Discovery of Grounded Theory: Strategies for Qualitative

Research. Chicago: Aldine.

Hartney, E. (2006) How to Manage Stress in FE: Applying Research, Theory and Skills to Postcompulsory Education and Training. London: Continuum.

HefCe (2003) Occupational Stress in Higher Education Institutions, Version 3. Exeter:

University of Plymouth.

HOGG, M. \& VAUGHn, G. (1995) Social Psychology. London: Prentice Hall.

holmes, T. H. \& RAHe, R. H. (1967) 'The Social Readjustment Rating Scale', Journal of

Psychosomatic Research 11(2): 213-18.

laZarus, R. \& FOlKman, S. (1984) Stress, Appraisal and Coping. New York: Springer.

LEACH, D. \& CONTO, H. (1999) 'The Additional Effects of Process and Outcome

Feedback Following Brief In-service Teacher Training', Educational Psychology 19(4):

441-62.

mCniff, J., lomax, P. \& Whitehead, J. (1996) You and You Action Research Project. London:

Routledge.

Mutch, A. (2003) 'Exploring the Practice of Feedback to Students', Active Learning in

Higher Education 4(1): 24-38.

SELYE H. (1956) The Stress of Life. New York: McGraw-Hill.

SMith, C. \& KING, P. (2004) 'Student Feedback Sensitivity and the Efficacy of

Feedback Interventions in Public Speaking Performance Improvement',

Communication Education 53(3): 203-16. 
Stough, L. \& Emmer, E. (1998) 'Teachers' Emotions and Test Feedback', Qualitative Studies in Education 11(2): 341-61.

TARis, T., VAN HORN, J., SCHAufeli, W. \& SChreurs, p. (2004) 'Inequity, Burnout and Psychological Withdrawal among Teachers: A Dynamic Exchange Model’, Anxiety, Stress \& Coping 17(1): 103-22.

thorndike, E. (1927) 'The Law of Effect', American Journal of Psychology 39: 212-22. VAN VONDEREN, A. \& DE BRESSeR, A. (2005) 'The Effect of Supervisory Feedback, Self-recording, and Graphic Feedback on Trainer Behavior During One-to-one Training', Behavioral Interventions 20(4): 273-84.

WALFORD, C. (2004) Occupational Stress in Staff within Medical Schools. Unpublished dissertation for the MSc Occupational Health and Safety at London South Bank University.

Waterman, H. (1998) 'Embracing Ambiguities and Valuing Ourselves: Issues of Validity in Action Research’, Journal of Advanced Nursing 28(1): 101-5.

Weiner, B. (1986) An Attributional Theory of Motivation and Emotion. New York: Springer Verlag.

Weiner, B. (2000) 'Intrapersonal and Interpersonal Theories of Motivation from an Attributional Perspective’, Educational Psychology Review 12(1): 1-14.

Weiner, B. \& KUKLA, A. (1970) 'An Attributional Analysis of Achievement

Motivation', Journal of Personality and Social Psychology 15(1): 1-20.

Winter, R. (1996) 'Some Principles and Procedures for the Conduct of Action

Research', in O. Zuber-Skerritt (ed.) New Directions in Action Research, pp. 13-27.

London: Falmer Press.

YounG, P. (2000) “'I Might as Well Give Up”: Self Esteem and Mature Students'

Feelings about Feedback on Assignments', Journal of Further and Higher Education 24(3):

409-18.

\section{Biographical note}

elizabeth hartney is a Chartered Health Psychologist, and a Senior Lecturer in Psychology and Counselling at the University of Greenwich. Previously, she has worked in the management of chronic stress and pain. She has recently written a book titled How to Mangage Stress in FE: Applying Research, Theory and Skills to Post-compulsory Education and Training, published by Continuum.

Address: University of Greenwich, Avery Hill Road, London SE9 2UG, UK. [email: info@drhartney.com] 